\title{
Germinação e vigor de sementes de urucu ${ }^{1}$
}

\author{
José Carlos Lopes; Renata V Lima; Célia Maria P Macedo \\ UFES-CCA, Dep ${ }^{\text {to. }}$ de Produção Vegetal, C. Postal 16, 29500-000 Alegre-ES; jclopes@cca.ufes.br; \\ renataviannalima2005@yahoo.com.br; celiampm@yahoo.com.br
}

\section{RESUMO}

Este trabalho foi desenvolvido com o objetivo de avaliar a germinação e o vigor de sementes de urucu (Bixa orellana L.) durante a maturação, efetuando-se amostragens 70, 77 e 84 após a antese (DAA). O estudo foi conduzido em duas etapas: na primeira utilizaram-se sementes intactas (controle) e sementes submetidas à escarificação mecânica com lixa de água $\mathrm{n}^{\circ} 100$, água quente a $70^{\circ} \mathrm{C}$ durante 1 , 3 e 5 minutos, resfriamento a $3^{\circ} \mathrm{C}$ durante sete dias, utilizando-se água destilada ou $\mathrm{KNO}_{3}$ no substrato. Na segunda etapa foi estudada a resposta de sementes (70, 77 e $84 \mathrm{DAA}$ ) ao envelhecimento acelerado $\left(42^{\circ} \mathrm{C}\right.$ e $100 \%$ de umidade relativa) por $0,12,24$, 36, 48, 60, 72, 84 e 96 horas. Em ambas as etapas, foram retiradas subamostras para avaliação. A germinação das sementes intactas, colhidas 70, 77 e 84 DAA, foi de 51, 53 e $16 \%$, respectivamente, e apenas os tratamentos em que se usou água quente $\left(70^{\circ} \mathrm{C}\right)$ causaram alteração significativa. Embora tenha impedido a germinação das sementes coletadas 70 DAA, a termoterapia por 1 e 3 minutos promoveu germinação superior ao controle nas sementes colhidas 84 DAA (62 e 55\%, respectivamente). Nas sementes intactas, o índice de velocidade de germinação (IVG) das sementes coletadas 84 DAA $(0,51)$ foi significativamente inferior ao daquelas coletadas $70(1,90)$ e 77 DAA $(2,32)$. Entretanto, a termoterapia foi eficiente em aumentar significativamente o IVG das sementes coletadas 84 DAA (1,65, 3,03 e 1,83, respectivamente para 1 , 3 e 5 minutos de imersão), sugerindo a existência de dormência das sementes após o provável ponto de maturação fisiológica (84 DAA). Em sementes coletadas 70 DAA, o envelhecimento acelerado até 96 horas não alterou a germinação. Em sementes colhidas 77 e 84 DAA, a germinação reduziu-se com o aumento do período de exposição ao envelhecimento acelerado. Sementes colhidas 70 DAA originaram a maior porcentagem de plântulas normais.

Palavras-chave: Bixa orellana L., dormência, envelhecimento acelerado, emergência, maturação de sementes.

\begin{abstract}
Annatto seeds germination at different maturation stadia

This research was carried out to evaluate the germination and vigor of annatto seeds (Bixa orellana L.) during maturation, collecting samples 70, 77, and 84 days after anthesis (DAA). The research consisted of two phases: first, seed samples of each harvest were submitted to different treatments: (i) mechanical scarification; (ii) thermotherapy $\left(70^{\circ} \mathrm{C}\right.$ in water bath) for 1,2 , and $3 \mathrm{~min}$; (iii) prechilling at $3^{\circ} \mathrm{C}$ during seven days, using distilled water or $\mathrm{KNO}_{3}$ solution to moist the paper towel, and untreated intact seeds (control). In the second phase, seed samples $(70,77$, and $84 \mathrm{DAA})$ were submitted to accelerated aging (AA) $\left(42^{\circ} \mathrm{C}, 100 \%\right.$ relative humidity) for $0,12,24,36,48,60,72,84$, and 96 hours. In both phases, seeds were sub sampled for evaluation. The germination of intact seeds collected 70, 77, and 84 DAA was 51, 53, and 16\%, respectively, and thermotherapy was the only treatment that significantly altered it. Although hindering the germination of seeds collected 70 DAA, thermotherapy for 1 and 3 minutes enhanced germination in seeds collected 84 DAA (62 and 55\%, respectively). In intact seeds, the germination rate (GR) of seeds collected 84 DAA (0.51) was significantly lower than in seeds collected 70 (1.90) and 77 DAA (2.32). However, thermotherapy significantly increased GR for seeds collected at 84 DAA $(1.65,3.03,1.83$, respectively for 1,3 , and 5 minutes of immersion), which suggests the occurrence of dormancy after the alleged physiological maturation point (84 DAA). For seeds collected 70 DAA, accelerated aging (AA) up to 96 hours did not interfered in germination. For seeds collected 77 and 84 DAA, germination decreased as exposure time to AA increased. Seeds collected 70 DAA had the highest proportion of regular seedlings.
\end{abstract}

Keywords: Bixa orellana L., lipstick tree, dormancy, accelerated aging, emergence, seed maturation.

\section{(Recebido para publicação em 8 de abril de 2007; aceito em 20 de fevereiro de 2008)}

\begin{abstract}
A espécie Bixa orellana L., conhecida vulgarmente como urucu, reúne plantas perenes e é característica da floresta amazônica de várzea. Seu cultivo deve-se à importância econômica de suas sementes condimentares e tintoriais. O urucuzeiro pode ainda ser
\end{abstract}

explorado como planta ornamental e para recuperação de áreas degradadas, devido à rapidez de crescimento (Lorenzi, 1998). O urucuzeiro vegeta bem em locais onde a temperatura oscila entre $24^{\circ}$ e $27^{\circ} \mathrm{C}$, com precipitação abundante (superior a $1.200 \mathrm{~mm}$ anuais) e solo bem drenado. Por ser uma planta rústica, o urucuzeiro cresce bem em terrenos de fertilidade média, suportando também baixos níveis de nitrogênio, fósforo e potássio (Ramalho et al.,1988; Cavalieri, 1991). Segundo Gomes \& Bruno (1992), a cultura do urucu vem

${ }^{1}$ Parte da dissertação apresentada à UFES-CCA pelo segundo autor para obtenção do título de mestre em Produção Vegetal. 
se expandindo face às perspectivas favoráveis de aumentar o uso industrial e as exportações de seus grãos.

Embora possa ser propagada por estaquia ou enxertia (borbulhia), sua propagação por semente é o método mais utilizado pelos agricultores. Pode ser feita semeadura direta em sementeiras ou em sacos plásticos. Para que apresentem alto poder germinativo, seus frutos (cápsulas) devem ser colhidos em seu melhor estádio de maturação e as sementes devem ser secas à sombra (Ramalho et al., 1988). Devido à importância do uso das sementes para propagação do urucu, torna-se urgente direcionar e intensificar os estudos sobre a germinação das sementes desta espécie, objetivando não só fornecer subsídios para sua propagação, mas também auxiliar o manual de Regras para Análise de Sementes (Brasil, 1992).

Segundo Popinigis (1985), a maturação compreende as transformações morfológicas, fisiológicas e funcionais que se processam no óvulo fecundado, culminando com o peso máximo de matéria seca, estádio em que a semente atinge também maior capacidade germinativa e vigor. Entretanto, vários autores têm encontrado dificuldades em germinar sementes de muitas espécies após a sua completa maturação, devido, principalmente, ao fenômeno da dormência. Segundo Carvalho \& Nakagawa (2000), a dormência é controlada por fatores endógenos e se caracteriza pelo fato das sementes, mesmo sendo viáveis e tendo todas as condições ambientais para tanto, como umidade, temperatura e oxigênio, deixam de germinar.

O envelhecimento acelerado é um teste de vigor baseado na simulação de fatores ambientais adversos de alta temperatura $\left(40-45^{\circ} \mathrm{C}\right)$ e umidade relativa (100\%) durante certo período para, posteriormente, observar as respostas das sementes pelo teste padrão de germinação (Wetzel, 1972) O teste de envelhecimento acelerado avalia a sensibilidade das sementes a esses fatores adversos mediante a sua manutenção no interior da câmara de envelhecimento por um período capaz de permitir a identificação de diferentes níveis de vigor (Marcos Filho et al., 1987). O objetivo deste trabalho foi avaliar a germinação e o vigor de sementes de urucu em diferentes estádios de maturação.

\section{MATERIAL E MÉTODOS}

Este trabalho foi desenvolvido no Laboratório de Tecnologia e Análise de Sementes do Depto. de Fitotecnia do CCA da UFES, em Alegre (ES). Foram utilizadas sementes de urucu, cultivar Casca Verde, provenientes da mesma região. As sementes foram coletadas em três estádios de maturação (70, 77 e 84 dias após a antese (DAA)). Os tratamentos foram constituídos por sementes intactas (controle); sementes escarificadas mecanicamente com lixa d’água $\mathrm{n}^{\text {o. }} 100$; sementes tratadas com água quente a $70^{\circ} \mathrm{C}$ durante 1 , 3 e 5 minutos e; sementes resfriadas a $3^{\circ} \mathrm{C}$ durante sete dias, utilizando água destilada ou $\mathrm{KNO}_{3}$ no substrato. Foram conduzidos os seguintes testes para avaliação do comportamento das sementes: 1 . teor de água - foi determinado nos frutos e sementes durante a fase de maturação e após a exposição das sementes ao envelhecimento acelerado, utilizando-se duas subamostras de cinco frutos ou 25 sementes para cada tratamento, adotando-se o método de estufa a $105^{\circ} \mathrm{C}$ por 24 horas (Brasil, 1992); 2. germinação - foi realizada com quatro subamostras de 50 sementes, tratadas com hipoclorito de sódio a $2 \%$ durante 10 minutos, distribuídas em rolos de papel Germitest ${ }^{a}$, umedecidos com um volume de água destilada equivalente a 2,5 vezes o peso do substrato seco e mantidos em germinador a $20-30^{\circ} \mathrm{C}$. As avaliações foram realizadas diariamente após a instalação do teste, considerando a protrusão da raiz primária maior ou igual a dois milímetros e, no final do teste, computando-se as porcentagens de plântulas normais, anormais, sementes dormentes (avaliadas pelo teste de tetrazólio) e sementes mortas (Brasil, 1992); 3. índice de velocidade de germinação -determinado mediante a contagem diária do número de sementes germinadas, isto é, aquelas que apresentavam protrusão de raiz primária maior ou igual a dois milímetros de comprimento, até a estabilização da germinação (Maguire, 1962); 4. envelhecimen- to acelerado - conduzido com as sementes coletadas nos três períodos de maturação, utilizando-se 250 sementes por subamostra, com quatro repetições de 50 sementes e duas de 25 para determinação do teor de água. As sementes foram colocadas em sacos de malha, em placas de Petri e, a intervalos de 12 horas, levadas à câmara de envelhecimento acelerado, a $42^{\circ} \mathrm{C}$ e $100 \%$ de umidade relativa, durante $0,12,24,36,48,60$, 72, 84 e 96 horas. As sementes foram tratadas com solução de hipoclorito de sódio a $2 \%$, durante 10 minutos, antes e após o período de envelhecimento. Posteriormente, procederam-se às avaliações do teor de água e germinação, conforme descrito anteriormente. Foram avaliadas também as massas fresca e seca de plântulas normais, 30 dias após a semeadura, mediante secagem a $80^{\circ} \mathrm{C}$ em estufa, durante 72 horas ou até atingirem peso constante.

O delineamento experimental utilizado foi inteiramente casualizado, com quatro repetições de 50 sementes. Os dados foram submetidos à análise de variância e teste $\mathrm{F}$, utilizando-se o esquema fatorial 3 x 7 nos tratamentos prégerminativos (três estádios de maturação e sete tratamentos nas sementes) e 3 x 9 no envelhecimento acelerado (três estádios de maturação e nove períodos de exposição). Os dados expressos em porcentagem foram transformados para arco seno “ $\mathrm{x} / 100 \mathrm{e}$, os valores do índice de velocidade de germinação, para " $x+0,5$, para fins de análise estatística. As médias foram comparadas pelo teste de Tukey $(\mathrm{p}<0,05)$. Os resultados do teste de envelhecimento acelerado foram analisados através de regressão polinomial.

\section{RESULTADOS E DISCUSSÃO}

O teor de água dos frutos durante as fases de maturação (Figura 1A), permaneceu constante até 70 dias após a antese (DAA) (74,7\%), reduzindo-se drasticamente de 77 (33,8\%) até 84 DAA $(13,7 \%)$, fases da maturação em que o desempenho das sementes foi avaliado. Nestas datas, as sementes apresentaram 71,5, 34,3 e 13,4\% de água, respectivamente (Figura 1B).

A protrusão da raiz primária das sementes em que não foi aplicado nenhum 


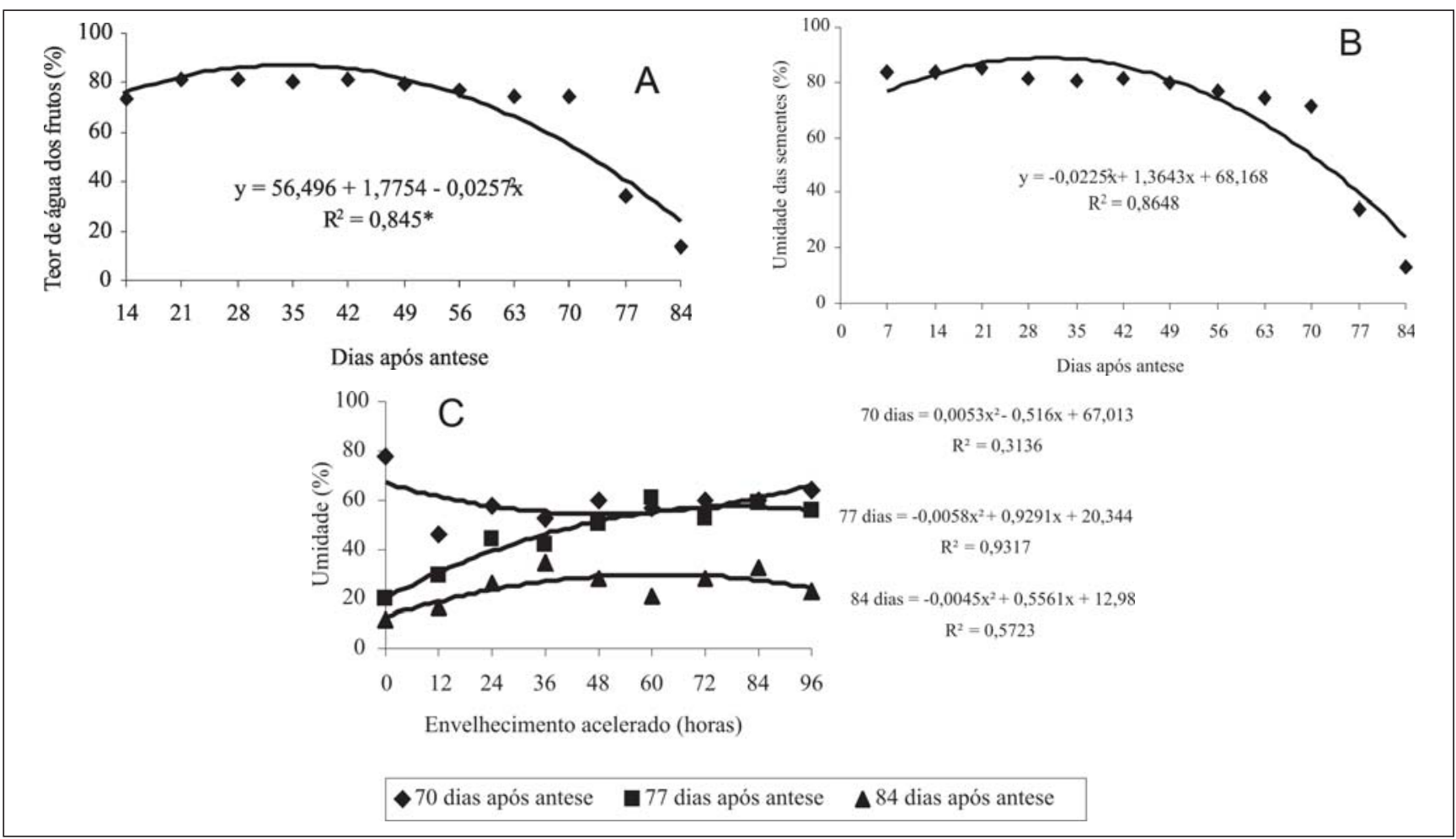

Figura 1. Umidade (\%) de frutos (A) e sementes (B) durante a maturação e umidade (\%) de sementes de urucu colhidas 70,77 e 84 dias após a antese e submetidas ao envelhecimento acelerado (C) (fruit (A) and seed (B) humidity (\%) during maturation and humidity (\%) of annatto seeds collected 70, 77, and 84 days after anthesis and exposed to accelerated aging (C)). Alegre, UFES, 2007.

Tabela 1. Germinação, índice de velocidade de germinação, sementes deterioradas e dormentes de urucu (germination, germination rate, deteriorated and dormant seeds of annatto at different maturation stages). Alegre, UFES, 2007.

\begin{tabular}{|c|c|c|c|c|c|c|}
\hline \multirow{2}{*}{$\begin{array}{l}\text { Tratamentos } \\
\text { A }\end{array}$} & \multicolumn{2}{|c|}{70 dias após antese } & \multicolumn{2}{|c|}{77 dias após antese } & \multicolumn{2}{|c|}{84 dias após antese } \\
\hline & Germinação (\%) & IVG1 $^{1}$ & Germinação (\%) & IVG1 & Germinação (\%) & IVG1 $^{1}$ \\
\hline Controle & $51 \mathrm{aA}$ & $1,90 \mathrm{aA}$ & $53 \mathrm{aA}$ & $2,32 \mathrm{aA}$ & $16 \mathrm{bB}$ & $0,51 \mathrm{cB}$ \\
\hline Escarificação & $36 \mathrm{aAB}$ & $1,56 a b B$ & $47 \mathrm{aA}$ & $3,48 a A$ & $24 \mathrm{bB}$ & $1,65 a b B$ \\
\hline Água $\left(70^{\circ} \mathrm{C}\right) 1^{\prime}$ & $0 \mathrm{bC}$ & $0 \mathrm{cC}$ & $18 \mathrm{bB}$ & $0,56 \mathrm{bB}$ & $62 \mathrm{aA}$ & $3,03 a A$ \\
\hline Água $\left(70^{\circ} \mathrm{C}\right) 3^{\prime}$ & $0 \mathrm{bB}$ & $0 \mathrm{cC}$ & $55 \mathrm{aA}$ & $2,88 a A$ & 55 aA & $1,83 a b B$ \\
\hline Água $\left(70^{\circ} \mathrm{C}\right) 5^{\prime}$ & $0 \mathrm{bB}$ & $0 \mathrm{cB}$ & $14 \mathrm{bA}$ & $0,48 \mathrm{bA}$ & $17 \mathrm{bA}$ & $0,45 \mathrm{cA}$ \\
\hline Resfriamento em $\mathrm{H}_{2} \mathrm{O}$ & $52 \mathrm{aA}$ & $1,07 a b A$ & $54 \mathrm{aA}$ & $1,00 \mathrm{bA}$ & $18 \mathrm{bB}$ & $0,27 \mathrm{cB}$ \\
\hline Resfriamento em $\mathrm{KNO}_{3}$ & $45 \mathrm{aA}$ & $0,79 \mathrm{bA}$ & $42 \mathrm{aA}$ & $0,78 \mathrm{bA}$ & $16 \mathrm{bB}$ & $0,21 \mathrm{cB}$ \\
\hline B & $\begin{array}{c}\text { Sementes } \\
\text { deterioradas } \\
(\%)\end{array}$ & $\begin{array}{c}\begin{array}{c}\text { Sementes } \\
\text { dormentes } \\
(\%)\end{array} \\
\end{array}$ & $\begin{array}{c}\text { Sementes } \\
\text { deterioradas } \\
(\%)\end{array}$ & $\begin{array}{c}\text { Sementes } \\
\text { dormentes } \\
(\%)\end{array}$ & $\begin{array}{c}\text { Sementes } \\
\text { deterioradas } \\
(\%)\end{array}$ & $\begin{array}{c}\text { Sementes } \\
\text { dormentes } \\
(\%)\end{array}$ \\
\hline Controle & $49 \mathrm{bA}$ & $0 \mathrm{aC}$ & $24 \mathrm{bcB}$ & $23 \mathrm{aB}$ & $35 \mathrm{bAB}$ & $49 \mathrm{aA}$ \\
\hline Escarificação & $64 a b A$ & $0 \mathrm{aA}$ & $53 \mathrm{aA}$ & $0 \mathrm{cA}$ & 76 aA & $0 \mathrm{cA}$ \\
\hline Água $\left(70^{\circ} \mathrm{C}\right) 1^{\prime}$ & $100 \mathrm{aA}$ & $0 \mathrm{aC}$ & $50 \mathrm{aB}$ & $32 a b A$ & $19 \mathrm{bC}$ & $19 \mathrm{bB}$ \\
\hline Água $\left(70^{\circ} \mathrm{C}\right) 3^{\prime}$ & $100 \mathrm{aA}$ & $0 \mathrm{aB}$ & $22 \mathrm{bcB}$ & $23 a b A$ & $35 \mathrm{bB}$ & $10 \mathrm{bA}$ \\
\hline Água $\left(70^{\circ} \mathrm{C}\right) 5^{\prime}$ & $100 \mathrm{aA}$ & $0 \mathrm{aB}$ & $44 a b B$ & $42 \mathrm{aA}$ & $44 a b B$ & $39 \mathrm{aA}$ \\
\hline Resfriamento em $\mathrm{H}_{2} \mathrm{O}$ & $48 \mathrm{bA}$ & $0 \mathrm{aB}$ & $21 \mathrm{cB}$ & $25 a b A$ & $46 a b A$ & 36 aA \\
\hline Resfriamento em $\mathrm{KNO}_{3}$ & $55 \mathrm{bA}$ & $0 \mathrm{aB}$ & 38 abcA & $20 \mathrm{bA}$ & $47 \mathrm{abA}$ & 37 aA \\
\hline
\end{tabular}

Médias de uma mesma característica, seguidas de mesma letra minúscula na coluna e maiúscula na linha, não diferem significativamente entre si pelo teste de Tukey, $\mathrm{p}<0,05 \%$ (means for the same characteristic, followed by the same small letter in the column and the capital letter in the row, did not differ from each other, Tukey’s test, $\mathrm{p}<0.05 \%$ ); ${ }^{1 / \mathrm{IVG}}=$ índice de velocidade de germinação (germination rate).

tratamento, colhidas 70, 77 e 84 DAA foi de 51,53 e $16 \%$, respectivamente (Tabela 1A). A escarificação mecânica e os tratamentos feitos com resfriamento das sementes não exerceram influência na porcentagem de germinação em relação ao controle em nenhuma das datas de coleta. Já os tratamentos em que se usou água quente $\left(70^{\circ} \mathrm{C}\right)$, embora tenham impedido a germinação das sementes coletadas $70 \mathrm{DAA}$, promoveram germinação significativamente similar 


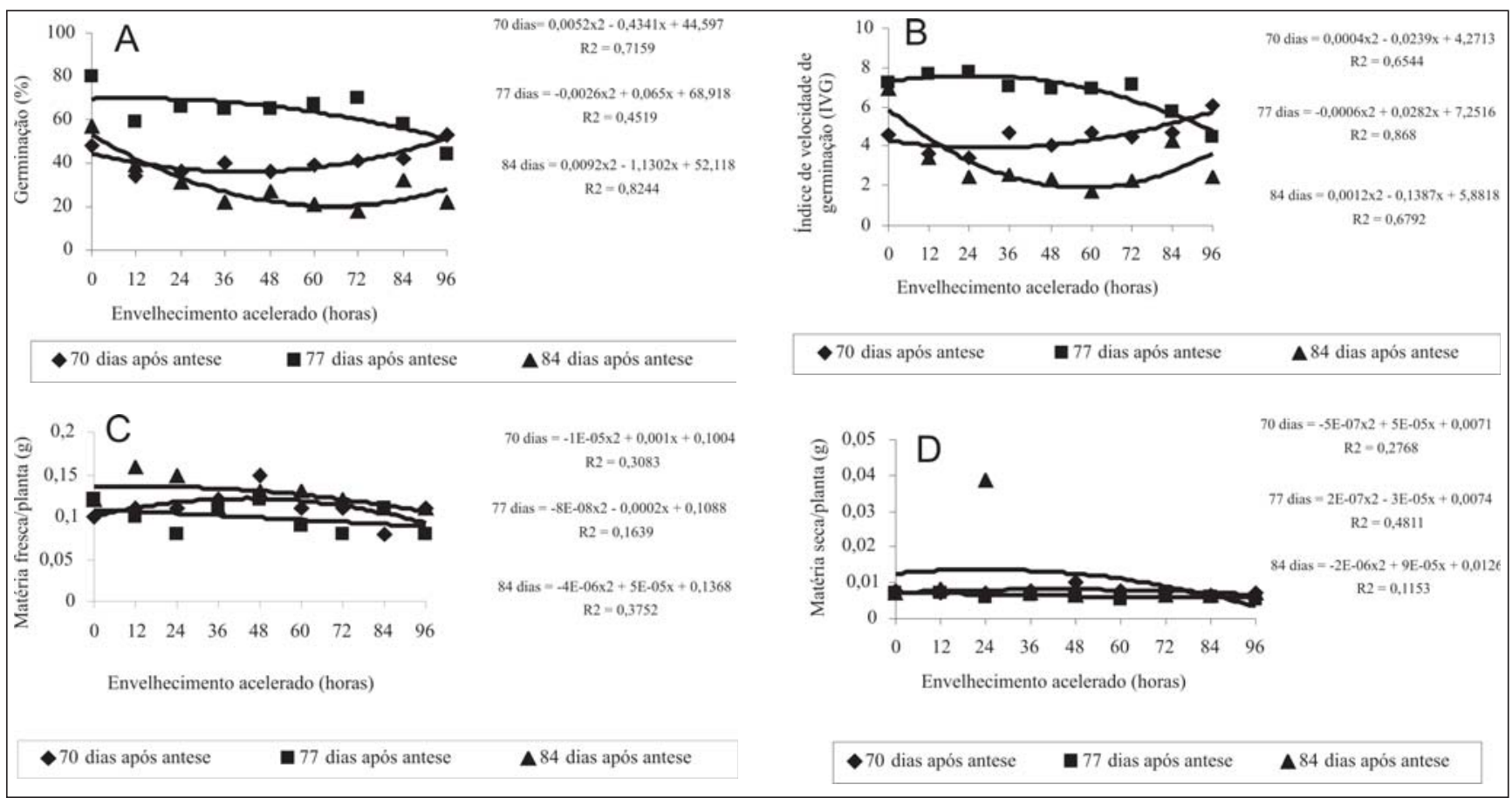

Figura 2. Germinação (\%) (A) e índice de velocidade de germinação (IVG) (B) de sementes de urucu colhidas em diferentes estádios de maturação e submetidas ao envelhecimento acelerado e massa fresca (C) e seca (D) de plântulas de urucu oriundas dessas sementes (germination (\%) (A) and germination rate (IVG) (B) of annatto seeds collected in different maturation stages and exposed to accelerated aging, and fresh (C) and dry mass of the seedlings borne from these seeds). Alegre, UFES, 2007.

ao controle nas sementes coletadas 77 DAA (apenas para imersão por três minutos) e germinação superior ao controle nas sementes coletadas 84 DAA, para 1 e 3 minutos (Tabela 1A).

Nas sementes que não sofreram nenhum tratamento, a velocidade de germinação das sementes coletadas 84 DAA foi significativamente inferior à das sementes coletadas nas demais datas (Tabela 1A). Entretanto, quando as sementes coletadas 84 DAA foram submetidas à termoterapia, o índice de velocidade de germinação (IVG) foi superior a todos os demais tratamentos para esta mesma data de coleta, concordando com os resultados obtidos na porcentagem de germinação. Esses resultados evidenciam redução na porcentagem de germinação das sementes de urucu após o provável ponto de maturação fisiológica atingido com a seca e deiscência dos frutos, observada com 84 DAA. A elevação do IVG com a termoterapia sugere ainda algum mecanismo de dormência das sementes de urucu, provavelmente relacionada à dureza e impermeabilidade do tegumento à água (Bewley \& Black, 1994). De acordo com Sahai \& Pal (1995), essa barreira pode estar associada à formação de uma camada de pectina na face superior das células palissádicas. Amaral et al. (1995) afirmaram que as sementes de urucu apresentam dormência imposta pela testa.

A análise das sementes que não germinaram mostrou que aquelas provenientes de frutos colhidos 70 DAA, quando frutos e sementes ainda se encontravam verdes, não apresentavam dureza do tegumento, o que facilita a sua morte, impedindo o aparecimento de sementes dormentes. Nesse ponto, o tratamento com termoterapia causou a morte de $100 \%$ das sementes, em todos os tempos de exposição. Em sementes oriundas de frutos colhido 77 DAA, também utilizadas como controle, não houve diferença significativa no número de sementes mortas (24\%) e dormentes (23\%). Já em sementes oriundas de frutos colhidos 84 DAA, estádio em que os frutos se encontravam em ponto de deiscência e as sementes apresentavam tegumento bastante rígido, houve maior ocorrência de sementes dormentes (49\%) do que sementes mortas (35\%) (Tabela 1B).

Na avaliação das sementes após os tratamentos com temperatura e umida- de relativa elevadas (envelhecimento acelerado), verificou-se que as mesmas apresentavam grau de umidade inicial de 77,6, 23,8 e 11,6\% nas colheitas realizadas 70, 77 e 84 DAA, respectivamente (Figura 1C). O teor de água das sementes, antes e após o envelhecimento acelerado, foi monitorado de acordo com Hampton \& Tekrony (1995) e Marcos Filho (1999), mantendo-se inicialmente em $11,6 \%$ nas sementes colhidas 84 DAA, sementes completamente maduras, frutos em estádio de deiscência e sementes com máximo teor de massa seca. O teor de água das sementes colhidas 70 e 77 DAA, embora bastante elevado em relação às sementes colhidas 84 DAA, não foi reduzido para evitar danos às membranas. De acordo com Simon (1978) altas e baixas temperaturas provocam redução na germinabilidade devido à inabilidade das membranas da semente para funcionar eficientemente como membranas semipermeáveis. De acordo com Panobianco \& Marcos Filho (2001), o controle do teor de água das sementes é importante na execução dos testes de envelhecimento precoce, uma vez que é fundamental para a padronização das 


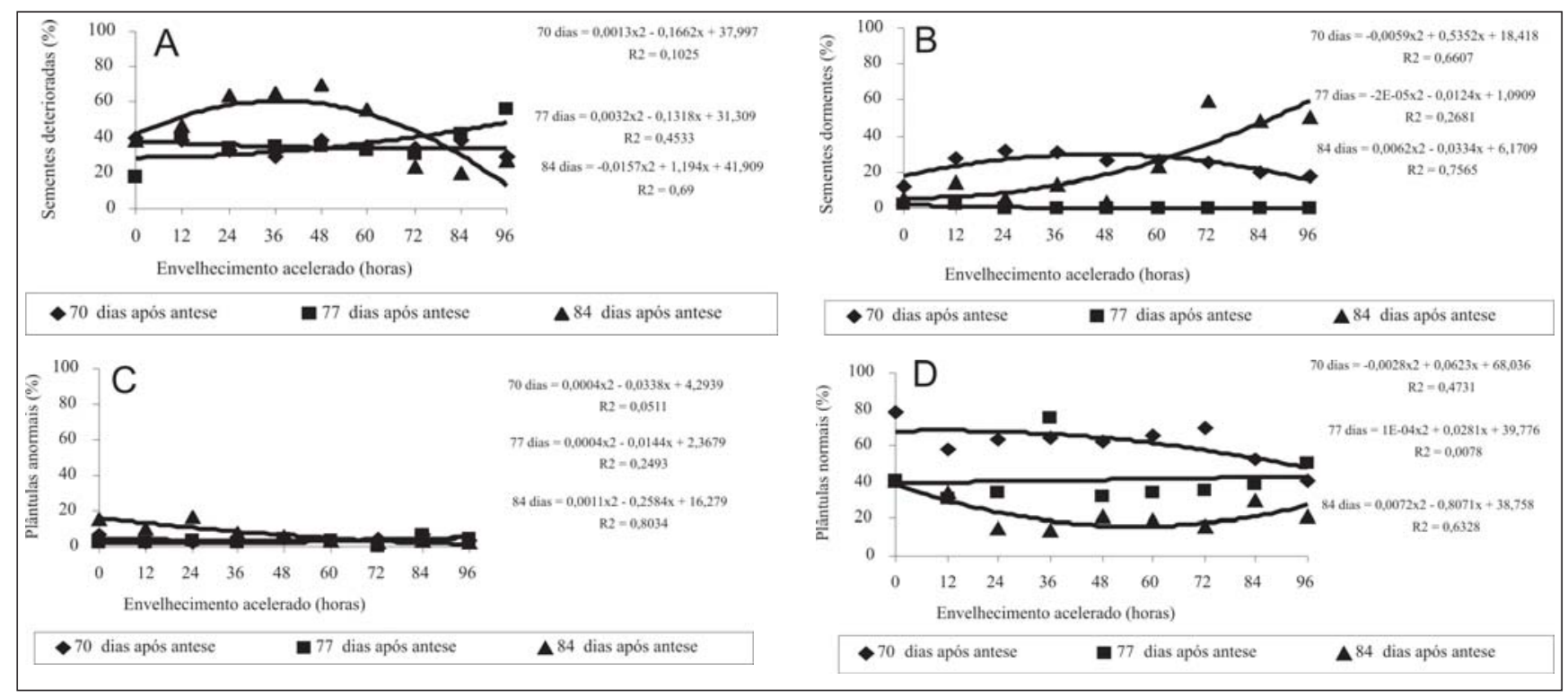

Figura 3. Sementes deterioradas (\%) (A) e dormentes (\%) (B) de urucu colhidas em diferentes estádios de maturação e submetidas ao envelhecimento acelerado e plântulas anormais (\%) (C) e normais (\%) (D) oriundas dessas sementes (deteriorated (\%) (A) and dormant (\%) (B) annatto seeds collected in different maturation stages and exposed to accelerated aging, and abnormal (\%) (C) and regular (\%) (D) seedlings borne from these seeds). Alegre, UFES, 2007.

avaliações e obtenção de resultados consistentes.

Após exposição à câmara de envelhecimento acelerado (Figura 1C), as sementes com 70 DAA, que apresentavam cerca de $77,6 \%$ de água, registraram redução progressiva e paulatina de umidade, culminando com $64 \%$ de água após 96 horas de exposição $\left(\mathrm{R}^{2}=0,31\right)$. As sementes com 77 DAA apresentavam $23,8 \%$ de umidade após a colheita e apresentaram aumento progressivo até 96 horas de tratamento, culminando com valores de aproximadamente $56 \%\left(\mathrm{R}^{2}=\right.$ 0,93). Já as sementes com 84 DAA, que na colheita apresentavam umidade de $11,6 \%$, apresentaram maior oscilação desses valores, chegando a aproximadamente $28 \%$ de umidade ao final das 96 horas de exposição na câmara $\left(\mathrm{R}^{2}=\right.$ 0,57). Ramos \& Carneiro (1991), estudando o envelhecimento artificial de sementes do Pinheiro do Paraná, observaram aumento no teor de umidade das sementes em função do tempo de exposição.

O teste de germinação, em função do grau de maturação, evidencia que sementes oriundas de frutos coletados 70 DAA apresentaram menor germinação e praticamente não apresentaram variações acentuadas nesse parâmetro com o tempo de exposição até 96 horas
(Figura 2A). Borges et al. (1992) trabalhando com envelhecimento acelerado em sementes de Piptadenia communis, também verificaram redução na viabilidade e na velocidade de germinação com o aumento do tempo de exposição das sementes ao envelhecimento. Em sementes oriundas de frutos colhidos 70 DAA, a germinação obtida em sementes não tratadas (controle) foi de $48 \%$ e os tratamentos feitos com envelhecimento acelerado até 96 horas não exerceram influência na capacidade germinativa das sementes $\left(\mathrm{R}^{2}=0,71\right)$. Sementes oriundas de frutos colhidos 77 DAA apresentaram germinação inicial de $80 \%$ (sementes não tratadas), reduzida paulatinamente de acordo com o aumento do período de exposição ao envelhecimento acelerado, culminando com 44\% de germinação após 96 horas $\left(R^{2}=0,45\right)$ (Figura 2A). A maior porcentagem de germinação nas sementes não tratadas colhidas 77 DAA pode estar relacionada à menor impermeabilidade do tegumento (Bewley \& Black, 1994). Sementes de frutos colhidos 84 DAA, apresentaram germinação inicial de $57 \%$, progressivamente reduzida com o tempo de exposição, atingindo valor de $22 \%$ após 96 horas $\left(\mathrm{R}^{2}=0,82\right)$. As oscilações e desuniformidades de resultados verificadas nestas análises podem ser atribuídas ao período de colheita das sementes durante a maturação e ao grau de umidade inicial da semente. De acordo com Marcos Filho (1994), temperatura, período de exposição das sementes, grau de umidade das sementes, abertura da câmara durante o teste, tratamento fúngico, tamanho da amostra, condições de germinação após o envelhecimento e o genótipo podem afetar o comportamento das sementes durante o teste. Em sementes oriundas de frutos colhidos 77 DAA pôde-se verificar que o índice de velocidade de germinação (IVG) foi maior e permaneceu praticamente inalterado até 72 horas de exposição, decaindo nos dois últimos períodos de envelhecimento $\left(\mathrm{R}^{2}=0,86\right)$ (Figura 2B), fato contrário ao observado em sementes oriundas de frutos colhidos 70 DAA, em que o índice de velocidade de germinação se manteve praticamente inalterado durante o transcorrer dos períodos de envelhecimento $\left(\mathrm{R}^{2}=\right.$ $0,65)$ e 84 DAA, em que sementes sem tratamento mostraram valores ainda mais altos para o IVG decaindo a partir de 12 horas de envelhecimento e se mantendo praticamente constante a partir desse ponto $\left(R^{2}=0,67\right)$.

Para as sementes oriundas dos frutos nos diferentes estádios de maturação, as massas fresca e seca de plântulas permaneceram praticamente inalteradas 
durante todos os períodos de envelhecimento (Figura 2C e 2D), sugerindo que nas três fases de coleta (70, 77 e 84 DAA), as sementes já haviam entrado em fase de maturação, maior acúmulo de substâncias de reserva.

Verificou-se aumento gradativo na porcentagem de sementes mortas (deterioradas) oriundas de frutos coletados 84 DAA, envelhecidas até 48 horas (Figura 3A). A partir desse ponto, houve uma queda progressiva na deterioração e aumento gradativo no número de sementes dormentes (Figura 3B). Nessa fase da maturação verificou-se início da abertura dos frutos (deiscência) e maior impermeabilidade do tegumento das sementes (Lopes et al., 2005). Fanti \& Peres (1999) verificaram que sementes de Adenanthera pavoniana L. submetidas ao envelhecimento acelerado não apresentaram superação da dormência imposta pela impermeabilidade do tegumento. O contrário foi observado em sementes oriundas de frutos coletados 70 e 77 DAA, onde se verificou aumento progressivo na deterioração e queda no número de sementes dormentes. Nessa fase o tegumento ainda não se encontrava totalmente impermeabilizado (Lopes et al., 2005) e, com processo de envelhecimento, as sementes perderam o vigor devido a uma série de fatores como o fenômeno de alteração na integridade das membranas (Heydecker, 1972). Com a perda de integridade das membranas, ocorre maior perda de solutos. Lopes (1990), em sementes de Phaseolus vulgaris L., verificou que durante o processo de envelhecimento, vão ocorrendo gradativamente eventos celulares que determinam a perda do padrão de distribuição do material protéico e o rompimento das paredes e membranas celulares dos cotilédones, além de alterações nucleares e desaparecimento de nucléolos, culminando com a deterioração das sementes.

Observou-se ainda que, nas sementes oriundas dos frutos em todos os estádios de maturação, os valores de plântulas anormais foram constantes para todos os períodos de exposição à câmara de envelhecimento acelerado
(Figura 3C), com maiores valores para sementes colhidas 84 DAA, sem tratamento e após 12 e 24 horas de exposição $\left(\mathrm{R}^{2}=0,80\right)$. As características evidenciadas nas plântulas foram: ausência ou bifurcação da raiz primária e ocorrência de plântulas raquíticas.

A análise de germinação mostrou que sementes colhidas 70 DAA originaram maiores porcentagens de plântulas normais, com desenvolvimento linear da raiz primária e presença de raízes secundárias; crescimento e diferenciação do hipocótilo, longo e cilíndrico, com coloração rosada na base e esverdeada em direção aos cotilédones. Os cotilédones apresentaram-se cordiformes e verdes e apresentaram queda progressiva à medida que se aumentou o tempo de exposição das sementes na câmara de envelhecimento $\left(\mathrm{R}^{2}=0,47\right)$. Sementes colhidas 77 DAA apresentaram valores aproximadamente constantes de plântulas normais com o aumento do tempo de exposição das mesmas na câmara, com maior ocorrência após 36 horas de exposição, enquanto sementes colhidas 84 DAA apresentaram valores mais baixos de plântulas normais com queda significativa após 24 horas de exposição na câmara, permanecendo constante após esse período $\left(R^{2}=0,63\right)$ (Figura 3D), fato que pode estar associado ao aumento da dormência e a redução verificada na porcentagem de germinação das sementes. Os resultados sugerem que as sementes de urucu coletadas 70 DAA apresentam capacidade germinativa, enquanto as sementes coletadas 84 DAA apresentam dormência e conseqüente redução na porcentagem de germinação. O envelhecimento acelerado das sementes coletadas 84 DAA destaca a germinação e o vigor e, naquelas coletadas após 77 DAA, há redução desses parâmetros. Em todos os tempos de exposição, o envelhecimento acelerado determinou redução da viabilidade das sementes com o aumento do tempo de permanência das sementes na câmara de envelhecimento.

\section{AGRADECIMENTOS}

Ao CNPq pela concessão de bolsa de estudo ao segundo autor.

\section{REFERÊNCIAS}

AMARAL LIV; PEREIRA MFA; CORTELAZZO AL. 1995. Quebra de dormência em sementes de Bixa orellana. Revista Brasileira de Fisiologia Vegetal 7: 151-157.

BEWLEY JD; BLACK M. 1994. Seeds: physiology of development and germination. 2.ed. New York: Plenum Press, 445p.

BORGES EEL; CASTRO JLD; BORGES RCG. 1992. Alterações fisiológicas em sementes de jacaré (Piptadenia communis) submetidas ao envelhecimento precoce. Revista Brasileira de Sementes 14: 9-12.

BRASIL. 1992. Ministério da Agricultura e Reforma Agrária. Regras para Análise de Sementes. Brasília: SNDA/DNDV/CLAV 365p.

CARVALHO NM; NAKAGAWA J. 2000. Sementes: ciência, tecnologia e produção. Campinas, Fundação Cargill, 4.ed. 588p.

CAVALIERI I. 1991. Culturas. Manchete Rural, Rio de Janeiro, n.55, p.81-82.

FANTI SC; PEREZ SCJGA. 1999. Influência do substrato e do envelhecimento acelerado na germinação de olho-de-dragão (Adenanthera pavoniana L. - Fabaceae). Revista Brasileira de Sementes 21: 135-141.

GOMES SMS; BRUNO RLA. 1992. Influência da temperatura e substratos na germinação de sementes de urucum (Bixa orellana L.). Revista Brasileira de Sementes 14: 47-50.

HAMPTON JG; TEKRONY DM. 1995. Handbook of vigour test methods. Zurich: ISTA.

HEYDECKER W. 1972. Vigour. In: ROBERTS EH. Viability of seeds. Syracuse University Press, v.1, p.209-252.

LOPES JC. 1990. Germinação de sementes de Phaseolus vulgaris. 223f. (Tese doutorado). Universidade Estadual de Campinas, Campinas.

LOPES JC; LIMA RV; MEIRA RMSA. 2005. Estrutura celular de sementes de urucu (Bixa orellana L.) em diferentes estádios de maturação e sua relação com a dormência. Informativo ABRATES, v.15, n. 1, 2, 3 (CDROOM).

LORENZI H. 1998. Árvores brasileiras: manual de identificação e cultivo de plantas arbóreas nativas do Brasil. Nova Odessa: Plantarum, v.1, 368p.

MAGUIRE JB. 1962. Speed of germination-aid in selection and evaluation for seedling emergence vigor. Crop Science, Madison, v.2, n.2, p.176-177.

MARCOS FILHO J. 1999. Teste de envelhecimento acelerado. In: KRZYZANOWSKI FC; VIEIRA RD; FRANÇA NETO JB. (eds.). Vigor de sementes: conceitos e testes. Londrina: ABRATES, cap 3, p.1-24.

MARCOS FILHO J. 1994. Teste de envelhecimento acelerado. In: VIEIRA, R.D.; CARVALHO, N.M. (Ed.). Teste de vigor em sementes. Jaboticabal: Funep, p.133-150. 
MARCOS-FILHO J; CÍCERO SM; SILVA WR. 1987. Avaliação da qualidade das sementes. Piracicaba: FEALQ, 230p.

PANOBIANCO M; MARCOS FILHO J. 2001. Envelhecimento acelerado e deterioração controlada em sementes de tomate. Scientia Agrícola 58: 525-531.

POPINIGIS F. 1985. Fisiologia da semente. Brasília: AGIPLAN. 289p.

RAMALHO RS; PINHEIRO AL; DINIZ GS. 1988. Urucum: planta rústica e de alto rendimento. A Lavoura, Rio de Janeiro, p.2431.
RAMOS A; CARNEIRO JGA. 1991. Envelhecimento artificial de sementes do Pinheiro do Paraná. Pesquisa Agropecuária Brasileira 26: 19-24.

SAHAI K; PAL A. 1995. Studies on seed treatments and histochemical characters of water barrier seed coat of Leucaena galuca (L.) Benth. Journal of Phytological Research 8: 97100.

SIMON EW. 1978. Membranes in dry and imbibing seeds. In: CROWE JH; CLEEG JS. ed. Dry Biological Systems. Academic Press, New York, p. 77-115.
WETZEL CT. 1972. Contribuição ao estudo da aplicação do teste de envelhecimento visando a avaliação do vigor em sementes de arroz (Oryza sativa L.), de trigo (Triticum aestivum L.) e de soja (Glycine max (L.) Merrill). $116 \mathrm{f}$. (Tese mestrado), Escola Superior de Agricultura “Luiz de Queiroz”/USP, Piracicaba. 